\title{
Corpos estigmatizados na Educação Física: distanciamentos e aproximações de um reconhecimento legítimo
}

\section{Stigmatized bodies in Physical Education: distances and approximations of a legitimate recognition}

\author{
Rafael Marques Garcia
}

\begin{abstract}
RESUMO: O presente texto tem por objetivo apresentar uma compreensão sobre corpos estigmatizados na área de conhecimento da Educação Física, discutindo sobre aspectos que tensionam normas importantes deste fenômeno. Nesse sentido, discutem-se teorizações fundamentais e clássica sobre norma, desvio, estigma e corpo, tendo por base central a noção do discurso reiterativo. Percebese que a Educação Física construiu sua identidade no Brasil até os anos de 1980 embasada em preceitos arraigados na ideia de um corpo sadio, forte e envolto pela cultura da fisicalidade, marcado especialmente por imposições diretivas, biomédicas e à serviço da lógica do mercado e das relações de produção capitalista, onde o corpo que não produz ou se distancia dos enquadramentos cartesianos clássicos da divisão corpo/mente e pensar/produzir foram - e ainda permanecem - estigmatizados.
\end{abstract}

PALAVRAS-CHAVE: Educação física; Norma; Estigma; Reconhecimento.

\begin{abstract}
This text aims to present an understanding of stigmatized bodies in the area of knowledge of Physical Education, discussing aspects that stress important norms of this phenomenon. In this sense, fundamental and classical theorizations about norm, deviation, stigma and body are discussed, having as a central basis the notion of reiterative discourse. It is noticed that Physical Education built its identity in Brazil until the 1980s based on precepts rooted in the idea of a healthy body, strong and surrounded by the culture of physicality, marked especially by directive, biomedical impositions and at the service of market logic and the relations of capitalist production, where the body that does not produce or distances itself from the classic Cartesian frameworks of the body/mind and thinking/producing division were - and still remain - stigmatized.
\end{abstract}

KEYWORDS: Physical Education; Standard; Stigma; Recognition.

\section{INTRODUÇÃO}

Este relato de experiência é oriundo da ferramenta de avaliação da disciplina "Corpo, Saúde e Mídia” ofertada pelos Programas Strictu Sensu de Pós-Graduação em Educação Física da Universidade Federal do Rio de Janeiro e Pós-Graduação em Ciências do Exercício e do Esporte da Universidade do Estado do Rio de Janeiro. Na disciplina, foram discutidos livros clássicos de Foucault, Bauman, Le Breton, José Rodrigues, Espinoza, dentre outros, com o intuito de compreender

\footnotetext{
${ }^{1}$ Professor substituto na Universidade Estadual do Maranhão/UEMA. Doutor em Educação Física. Membro do grupo de pesquisa Esporte, Corpo e Sociedade - GECOS. ORCID id: 0000-0002-0837-1493. E-mail: rafa.mgarcia@ hotmail.com 
como discursos se materializam nos/pelos corpos ao longo da historicidade. Ao final da disciplina, cada estudante teve de apresentar um texto sobre "Os estigmatizados e a Educação Física", utilizando como aporte teórico os livros debatidos ao longo do semestre e também outros que viessem a acrescentar nessa discussão.

Este ensaio é produto final da disciplina, tendo por objetivo apresentar uma compreensão sobre corpos estigmatizados na área de conhecimento da Educação Física, discutindo sobre aspectos que tensionam normas importantes deste fenômeno. Nesse sentido, discutem-se teorizações fundamentais e clássicas sobre norma, desvio, estigma e corpo, e ao final, correlacionam-se esses aspectos com a área "Educação Física" e os processos de subversão para reconhecimento legítimo dos corpos estigmatizados.

Para tanto, alguns autores e suas obras serão acionados como referenciais basilares neste momento, sendo: Vigiar e Punir, e a Ordem do Discurso, de Michel Foucault (2010; 1996, respectivamente); Estigma, de Erving Goffman (1988); A Sociologia do Corpo, de David Le Breton (2010); Tabu do Corpo, de José Rodrigues (1979); Educação Física escolar: as relações de gênero em jogo, de Helena Altmann (2015); Educação Física \& Ciência: cenas de um casamento (in)feliz, de Válter Bracht (1999); e Educação Física: raízes europeias, de Carmen Soares (2017).

\section{A NORMA, O DESVIO E O ESTIGMA}

O conceito de norma discutido por Michel Foucault e problematizada em muitas de suas obras, resgata na história da humanidade uma ideia central de organização e estruturação de todas as coisas que existem no mundo, no intuito de classificá-las à luz de um sistema de vida que seja útil, prático e rapidamente palpável. Nesse sentido, quando se fala sobre norma, é impossível desvencilhar-se da noção que se constrói para sistematizar e corrigir tudo aquilo que se vê, se vive e como as pessoas se colocam no mundo que as cerca. A norma faz parte de um conjunto de ações pelas quais o ser humano, dentro de um contexto sócio-histórico, político e cultural, vai organizar suas ações tanto no seio individual quanto coletivo; ela é importante para instaurar a ordem das coisas, numa espécie de vigilância constante que retifica tudo aquilo que dela destoa (FOUCAULT, 2010).

A partir dessa noção de organização estrutural e coletiva, o ser humano cria a norma em conjunto com aspectos importantes de sua cultura e identidade. O cenário que está posto irá influenciar para a adoção de medidas e condutas que naturalizarão certas práticas em detrimento de outras, e através da reiteração constante dessas práticas é que se estabelecerá o senso de naturalidade, por conseguinte, de normal a essas estruturações. O normal é, portanto, aquele que está bem enquadrado para os símbolos e significados de determinado grupo social. 
Ao discutir sobre o conceito de poder, Foucault (2010) retorna aos séculos passados para analisar a forma como as instituições sociais desempenharam papel crucial no estabelecimento de corpos aceitáveis e identificáveis dentro de civilizações pelo mundo. Vários são os artifícios pelos quais as instâncias sociais, tais como a igreja, as ciências biomédicas, a política, a família, etc., se utilizam para educar corpos dentro de uma perspectiva de norma social, que cria identidades facilmente identificáveis; e daí despontará uma outra norma, aquela que irá identificar um subgrupo dentro de um grupo; e surgirá outra dentro do subgrupo para normatizar mais um nicho dessa classificação, e assim por diante. A norma não tem fim: ela se constrói e se manifesta até mesmo pelas mais simples ações do dia-a-dia, como vestir uma roupa de determinada cor ou estilo, por exemplo.

Foucault explica que uma das principais formas de se arquitetar e manter uma norma é através dos discursos, não apenas os linguísticos, mas também aqueles arquitetônicos, de poder, de saber, inclusive do não-dito. O silenciamento de determinado assunto também é um discurso; a estranheza perante uma situação inovadora também constitui um discurso; as políticas públicas em educação e saúde constituem outro discurso; e por aí em diante. Todos, entretanto, sempre carregam consigo a particularidade do poder, que pode ser compreendida não como algo dado de forma inata e imutável, mas construído a partir de relações intra e interpessoais em um jogo simbólico de representações sociais. É daí que irá irromper a importância da norma, ou melhor, o poder da norma: a partir disso é que se atribui valor a determinada conduta social, não numa única e irrestrita forma de se expressar, mas em várias (FOUCAULT, 1996).

E dessa constante elaboração e implementações de normas é que surgirá a ideia de anormal: em suma, aquilo que não pertence à norma; compõe o cerne do desvio; aquilo que se quer evitar, pois trará o caos às ordens e ao controle da humanidade. $\mathrm{O}$ desviado, o anormal, é tudo aquilo que reconhece na norma sua potencialidade de destruição: a própria noção de norma, ao se estabelecer, também estabelece a anti-norma, isto é, por fixar fronteiras e delimitações daquilo que se diz aceitável, inexoravelmente se pinta também sua fronteira. Tudo aquilo que está além, que não é compreendido por essa estratificação, torna-se desvio (FOUCAULT, 1996; 2010; RODRIGUES, 1979).

Mas a constituição da norma é ampla. Ela não age sozinha. Uma sociedade normatizada já introjetou os elementos da norma e fará de tudo para que ela seja preservada, pois em síntese, representa o controle, o domínio, o poder. É através dela que se exerce o controle da população à serviço das instâncias do biopoder moderno; controlando-se a norma, controlam-se os corpos, as comunidades, as civilizações. Não à toa percebe-se esforços de religiosos, médicos, pais e mães, 
líderes de todos os setores e etc. para impor um padrão a ser seguido, uma espécie de roteiro de vida impecável que irá manter a ordem estrutural e civilizada das coisas.

A partir daí, tudo tem norma e desvio. São essas estruturas que reconhecerão e identificarão todos os setores, as áreas, as pessoas, enfim, absolutamente tudo nas sociedades. Portanto, não é possível pensar um mundo sem a existência da norma: ela está onipresente em tudo, mesmo que se pense o contrário. A norma ronda corpos, instituições, áreas, processos, saberes e toda forma de organização viva e não viva da Terra. Não está fixa, mas em transformação, sendo reflexo daquilo que a sociedade reconhece como válido ou não. A norma é maleável, desde que atenda aos interesses das instituições do poder, essas representadas por pessoas que, por sua vez, vivenciam aspectos do próprio poder (FOUCAULT, 2010).

Na esteira da noção do desvio é que surgirá o estigma. Para Goffman (1988), o estigma é aquilo que quer evitar, justamente por ser contrário à norma, ao normal; compõe a noção básico daquilo que seria abjeto, desprezível, insignificante. Para estabelecer esse reconhecimento, só é possível fazê-lo através da norma, dentro de um conjunto de valores simbólicos e físicos que elencam aspectos que são importantes e, em consequência, daqueles que não têm a mesma importância ou valorização. Quando se pensa em um estigma, fala-se de algo que deve ser combatido, repelido; também à serviço de uma norma, para manter a mesma ordem de determinado espaço, povo, cultura, etc.

Rodrigues (1979) comenta sobre o estigma sem, no entanto, nomeá-lo. Diz ser um processo impuro, que destoa daquilo que seria considerado válido - ou até mesmo sagrado para determinada forma de pensamento. Essas estruturas endossam o caráter de abjeção daquilo que desvia, do anormal, do estigmatizado: não tem valor, não tem importância; é menor, pequeno, desvalorizado, inútil. Não deve existir em uma sociedade disciplinada e pura, como já se destacam tantos relatos ao longo da história da humanidade através da adoção de políticas de extermínio de determinados povos e raças em vista da supremacia e eugenia de certos grupos.

\section{O CORPO}

O corpo humano, conforme afirmam Le Breton (2010) e Rodrigues (1979) vai muito além do que apenas um conjunto biológico de células e tecidos. O corpo se constrói e se reconstrói a partir de vários elementos de nosso universo social, trazendo para sua própria identidade marcas que o identificarão dentro de uma própria noção de norma, ou então, que o identificarão por ser um desvio de determinada norma.

O corpo é uma esfera maleável, onde a sociedade e o próprio sujeito projetam aquilo de mais significativo e pertinente à luz de seu contexto social. Desta forma, não é possível trabalhar apenas 
com o conceito de corpo no singular, mas sim no plural. Existem muitos corpos espalhados mundo afora, todos, embora semelhantes, únicos em suas particularidades. Os elementos que são valorizados por determinados grupos e constituem suas normas podem ser desvalorizados por outros e constituírem justamente sua anti-norma. E também, a noção que se tinha de um corpo normal em determinado período pode mudar de acordo com a modernização e/ou aparecimento de novos meios e mecanismos de se gerenciar o próprio corpo e seus marcadores sociais (LE BRETON, 2010).

Entretanto, a norma por vezes se manifesta de forma pouco maleável, como é o caso de corpos que são estigmatizados de modo geral. A ideia da normalidade física, à qual se estende e é utilizada amplamente pelas instituições sociais para organizar sua estrutura social em um universo majoritariamente capitalista, de produzir, sustentar e expandir as forças políticas de um EstadoNação, trouxe consigo pensamentos e valores que desqualificam corpos que não se apresentam de determinada maneira que seja interessante para o sistema.

Conforme destaca o sociólogo porto-riquenho Ramón Grosfoguel em seu texto "Descolonizar as esquerdas ocidentalizadas: para além das esquerdas eurocêntricas rumo a uma esquerda transmoderna descolonial" (2012, p. 343),

O homem branco, capitalista, heterossexual, militar, cristão, europeu foi o que se expandiu pelo mundo levando consigo, e impondo simultaneamente, os privilégios de sua posição racial, militar, de classe, sexual, epistêmica, espiritual e de gênero. Estas diversas e entrelaçadas colonialidades, foram cruciais nas hierarquias e ideologias globais que, ainda no início do século XXI, experienciamos em escala planetária.

Neste sentido, todo corpo que não interessa aos padrões sociais mais valorizados sofrerá com certo estigma, geralmente enunciando um marcador social da diferença, que é justamente o elemento que o identificará não apenas na similitude, mas também na própria adversidade. $\mathrm{O}$ pensamento hegemônico do branco colonizador e capitalista construiu uma ideia de que corpos que não se enquadram nos moldes iniciais do sistema de produção fabril iniciado no século XVIII com a Revolução Industrial é inútil, desprezível e desinteressante. Daí, por exemplo, não é difícil perceber o quanto políticas precárias aos corpos e às vidas estigmatizadas vêm avançando nos últimos anos, como reflexo de uma sociedade a favor da norma hegemônica e contra a anti-norma, que visa apagar qualquer coisa que remeta ao estigma e expurgá-lo das estruturas sociais.

Historicamente, esses processos já aconteceram com vários corpos: aqueles que apresentavam deficiência ao sistema, os de tom de pele negra, aqueles que eram desordeiros, incontroláveis, esquisitos; aqueles que cultivavam desejos e valores diferentes dos valorizados, tais como homossexuais e transexuais; mas ainda assim, existiria dentro da própria estrutura da norma, as 
instituições do poder para reeducar e "consertar" corpos desviantes da ordem (FOUCAULT, 2010). Esses elementos continuam embutidos nas sociedades, e já desde cedo aprende-se a como se portar, enquadrado em esquemas de vida que socialmente são mais valorizados que outros. Em vários momentos é possível se perceber repetindo essas formas de reprodução, recaindo na ideia de reiterabilidade dos próprios discursos normalizadores do corpo.

E molda-se o corpo a todo instante: sempre a serviço dos avanços e mudanças sociais, deixando-o próximo daquilo que comporá uma identidade válida, principalmente dentro de determinado segmento. Nesse sentido é que se discutirá a valorização de determinado corpo na Educação Física e como essa identidade pode ser boa por conferir a própria ideia de um campo "Educação Física”, mas também nociva por estabelecer aquilo que seria a anti-norma e, portanto, um estigma.

\section{A ÁREA "EDUCAÇÃO FÍSICA” E OS PROCESSOS DE SUBVERSÃO PARA O LEGÍTIMO RECONHECIMENTO DOS ESTIGMATIZADOS}

Quando se fala em Educação Física, já se estabelece uma norma, uma rotulação, algo que a identifique. Bracht (1999) dialoga com outros autores como Hugo Lovisolo e Mauro Betti para situar a Educação Física enquanto uma área de conhecimento, não uma ciência, mas um meio pelo qual se produzem ciências. Em linhas gerais, a Educação Física, conforme destaca o autor, não possui força para se consolidar como ciência propriamente dita porque não possui métodos de intervenção e tratamento próprios: está sempre passeando pelas outras ciências e utilizando-se delas para produzir seu próprio conhecimento (BRACHT, 1999).

A norma da Educação Física aí está posta. Altmann (2015) acrescenta que a área em questão lidará com a cultura corporal do movimento humano através de uma intervenção pedagógica, fundamentada na clássica obra do Coletivo de Autores, Metodologia do Ensino de Educação Física, de 1992. Quando discorre sobre as manifestações de gêneros e sexualidades nas aulas de Educação Física escolar, Altmann (2015) aborda a noção de estigma para amplificá-lo além do que apenas esses marcadores por ela trabalhados. A autora resgata no histórico da Educação Física brasileira os inúmeros processos de eugenia, da prática tecnicista, do ideal de corpo perfeito e da purificação da população para dizer que, a priori, a própria Educação Física se alicerça na estigmatização, o que só vem sendo tensionado a partir dos anos de 1980.

Neste sentido, os corpos estigmatizados na Educação Física seriam aqueles justamente contrapostos ao princípio da fisicalidade que, nos dizeres de Altmann (2015), é o corpo habilidoso, bem treinado e que representa de forma fidedigna o que se espera dele em determinado contexto em suma seria o corpo normatizado: onde nele se projetam os valores sociais mais significativos e se 
colhe desses elementos simbólicos. Assim sendo, aquele fisicamente com deformações, deficiências, corpo gordo, magro, muito alto, muito baixo, inábil ou incongruente com o que se espera da cultura de fisicalidade e do desempenho será estigmatizado; se materializará no aluno que será sempre o último a ser escolhido nas atividades escolares pelos seus colegas; por aquele que será excluído e impossibilitado de participar das práticas corporais propostas; aquele que será ojerizado quando se manifestar em determinados espaços onde se cultua um tipo de corpo produtivo à luz das normatizações do capitalismo moderno (SOARES, 2017).

Quando se pensa na Educação Física brasileira, fica difícil não lembrar do processo de estigmatização histórica que a acompanhou: num primeiro momento, era restrita aos alunos da Corte Real Portuguesa que aqui estavam, sendo os estigmatizados nesse contexto indígenas e a população negra, que tinham práticas consideradas pagãs e contrários ao bom treinamento do corpo pelo que se entendia até então do desenvolvimento dos métodos ginásticos europeus (SOARES, 2017).

Posteriormente, foram os corpos com deficiência física os estigmatizados, não apenas os que comprometiam as funções locomotoras do corpo, mas também aqueles que em termos de saúde pelo menos o que se compreendia de saúde na época - apresentavam restrições ou impossibilidades de uma prática física sistematizada. Mais à frente, os corpos não atléticos passaram a sofrer com a exclusão e estigma, quando não encontravam nas possibilidades das práticas corporais a abertura para participar de modo satisfatório do que era proposto (SOARES, 2017; ALTMANN, 2015).

Todos esses processos foram culminando numa identidade de Educação Física à luz de um corpo bem delineado, musculoso e sem excesso de gorduras, que fosse harmonioso e exuberante e remetesse à saúde. Já o estigma ficou para todo aquele corpo que rompesse com a ideia de saudável ou não fosse visualmente agradável ao padrão social de beleza que veio se desenvolvendo principalmente dos anos de 1970 em diante. Desta forma, criou-se uma capa de exibição da Educação Física esportivista, de um corpo definido e atlético e de exaltação das aspirações de uma ordem social, capitalista e cristã de um Estado-Nação: essa é a norma da Educação Física, e todo aquele que desvia, tornou-se o anti-norma, o estigma.

Como possibilidades de reconhecimento, outras formas de se entender e compreender o corpo nas práticas corporais e na Educação Física vieram sendo promovidas ao longo dos anos de 1980 em diante, como a criação de uma Educação Física popular (centrada na participação ampla e democrática da população), o EPT - Esporte Para Todos, que considera e valoriza participações múltiplas em atividades esportivas que não apenas aquelas voltados ao alto desempenho -, políticas públicas de ampliação de direitos às populações marginalizadas, entre outras.

A atenção aos aspectos de inclusão e reconhecimento das subjetividades passa, segundo Sassaki (2010, p. 41) por um processo social adaptativo de "incluir em seus sintomas sociais gerais 
pessoas com necessidades especiais e, simultaneamente, estas se preparam para assumirem seus papéis na sociedade". Essa participação e automação se dá pelas mesmas instâncias de poder que outrora contribuíam para a sustentação de estigmas e invisibilidades, mas que hoje reassumem novos papéis e funções frente às demandas atuais, tais como a família, a escola, a mídia, e a própria Educação Física.

As novas formas de ser/estar, se apresentar e se compreender enquanto pertencentes a uma sociedade e/ou cultura possibilitaram ressignificações políticas e individuais dos seres humanos, estendendo as possibilidades de se viver os corpos em múltiplos cenários sociais. Ao entender que não existe existência material do ser humano se não pelo corpo, percebe-se que o sujeito se vale de sua estrutura corpórea para centrar suas ações, relações e interações entre os modelos possíveis e/ou legítimos de se manifestar, gerando um processo identitário que, em conjunto, reconstrói os valores e os aspectos coletivos de determinados grupos. Daí, toda forma de inserção e vivência deveria ser reconhecida e abolida dos elementos estigmatizantes, gerando pertencimento, reconhecimento e existência dos sujeitos em todos os espaços, inclusive naqueles que não foram pensados para eles.

Há de se ressaltar, porém, que estigmas sociais ainda são latentes no Brasil, ainda mais no atual governo federal (2019-2022) com seu plano eugênico muito bem orquestrado, que continua insistindo em reproduzir normas singulares e que exterminam todo tipo de corpo que para eles não seja interessante. Nesse sentido, pensar num processo de democratização e reconhecimento dos corpos diversos se torna comprometido por esbarrar em entraves burocráticos e até mesmo de execução, onde o conservadorismo resgata e enaltece práticas até então consideradas inaceitáveis para as sociedades modernas, representando um retrocesso ao reconhecimento e manifestação das diversidades e diferenças.

\section{CONSIDERAÇÕES FINAIS}

A Educação Física, por ter construído sua identidade no Brasil até os anos de 1980, carrega consigo preceitos fortemente arraigados na ideia de corpo sadio, forte e envolto pela cultura da fisicalidade. Edificada antes das discussões renovadoras, a Educação Física criou sua identidade num momento marcado especialmente por imposições diretivas, biomédicas e à serviço da lógica do mercado e das relações de produção capitalista, onde o corpo que não produz ou se distancia dos enquadramentos cartesianos clássicos da divisão corpo/mente e pensar/produzir são estigmatizados. Por vezes, insiste-se em não se atualizar ou remodelar frente às necessidades da contemporaneidade.

O que se percebe é uma Educação Física ainda fortificada em normas do século XX, composta por pessoas que ainda pensam nessa identidade anterior e que desacreditam nos avanços e 
modificações promovidas por políticas públicas e as novas formas de se entender, compreender e se relacionar com o mundo atual.

\section{REFERÊNCIAS BIBLIOGRÁFICAS}

ALTMANN, Helena. Educação Física escolar: as relações de gênero em jogo. São Paulo: Cortez Editora, 2015.

BRACHT, Válter. Educação Física \& Ciência: cenas de um casamento (in)feliz. Ijuí/RJ: Ed. Unijuí, 1999.

FOUCAULT, Michel. Ordem do Discurso. São Paulo: Ed. Loyola, 1996.

FOUCAULT, Michel. Vigiar e Punir. Petrópolis/RJ: Vozes, 2010.

GOFFMAN, Erving. Estigma. Rio de Janeiro: Ed. LTC, 1988.

GROSFOGUEL, Ramón. Descolonizar as esquerdas ocidentalizadas: para além das esquerdas eurocêntricas rumo a uma esquerda transmoderna descolonial. Revista Contemporânea, São Carlos, v. 2 , n. 2 p. 337-362, jul./dez. 2012.

LE BRETON, David. A Sociologia do Corpo. Petrópolis/RJ: Vozes, 2010.

RODRIGUES, José Carlos. Tabu do Corpo. Rio de Janeiro: Ed. Achiamé, 1979.

SASSAKI, Romeu Kazumi. Inclusão: construindo uma sociedade para todos. 8. ed. Rio de Janeiro: WVA, 2010.

SOARES, Carmen. Educação Física: raízes europeias. São Paulo: Ed. Autores Associados, 2017. 